\title{
Optimization of Wear Parameters of Polyamide-6 Composite Materials Filled with Wollastonite Particles
}

\author{
Aslan ÇOBAN \\ Sakarya Univ. Faculty of Technical Education, \\ Department of Mechanical Education, Sakarya Turkey
}

\author{
Ahmet DEMIRER \\ Sakarya Univ. Faculty of Technical Education, \\ Department of Mechanical Education, Sakarya Turkey
}

\author{
Ferit FIÇICI \\ Sakarya Univ. Faculty of Technology, Department of \\ Mechanical Engineering, Sakarya Turkey
}

\begin{abstract}
Weight loss and friction coefficient prediction models for polyamide-6 (PA-6) composites filler with 0,5 and 10 wt.\% wollastonite $(W)$ particles was developed using Taguchi method by considering the parameters of sliding speed, applied load and filler ratio. The wear behavior of the specimen was investigated using pin-on-disc arrangement where the samples sliding against a AISI 4140 steel disk under different conditions. The wear tests were realized at the sliding speeds of 1.0, 1.5 and $2.0 \mathrm{~ms}-1$ and under the loads of 6, 10, and $20 \mathrm{~N}$. The obtained weight loss for with 5 and $10 \mathrm{wt} . \%$ wollastonite $(W)$ particles PA-6 composites are lower than pure PA-6 weight loss under the same test conditions. The orthogonal array, signal-to-noise ratio ( $S / N)$ and analysis of variance (ANOVA) were employed to study the optimal testing parameters on composite samples. The estimated $S / N$ ratio using the optimal testing parameters for specific wear rate were calculated and a good agreement was observed between the predicted and actual weight loss for a confidence level of $90 \%$.
\end{abstract}

Keywords: Polyamide6, Wollastonite,Wear test, Optimization

\section{Introduction}

Polymer and polymer based composites are preferred for many industrial sectors such as automotive, electrical/electronic, aircraft and household applications. This is because these materials provide high strength/weight ratio in comparison to classic material and self-lubricant conditions. However, application areas of polymeric materials are restricted due to their low mechanical, thermal and tribological properties. Therefore reinforcements are used to increase their mechanical properties [1].

The used reinforcement and additive materials are glass fibre [2]; [3], $\mathrm{CaCO} 3$, [4];[5], kaolin, [6]; [7], talc [8], wollastonite [9], and mica [10];[11] fillers and MoS2, graphite, carbon, wax, polytetrafluoroethylene (PTFE) and dry lubricants [12];[13]. Dry lubricants are materials which despite being in the solid phase, are able to reduce friction between two counterparts sliding against each other without the need for a liquid medium [14].

In engineering, PA was used for some components or parts of machines in chemical engineering, textile engineering, food processing, paper making industry, pharmacy, transportation engineering, agricultural engineering, coal and ceramic production, where PA-6 was substituted for carbon steel, stainless steel and bronze, because of its better anti-chemical-corrosion, water-repellent function, anti-adhesion, self-lubrication and higher impact resistance [15].

A relationship between the wear of the polymer matrix composites reinforcement and test parameters is desirable to obtain a better understanding of their wear behaviour. There have been numerous studies searching the influence of reinforcement, test conditions, contact geometry and environment on the tribological behaviour of polymer matrix.

Gordon and Kukureka [16] and Chen et al. [17] report that the friction coefficient can, generally, be reduced and the wear resistance increased by adding the reinforcement. Kim et al. [18], Yu et al. [19], Zhao et al. [20] and Samyn et al. [21], observed that the friction coefficient of polymers rubbing against metals decreases with the increase in load while Palabiyik and Bahadur [22] and Meng et al. [23] showed that its value increases with the increase in load.

In order to study the influence of AlB2 boride flakes on tribological properties of PA-6, PA-6 composites were produced by pressure moulding technique.

\section{Experimental Procedures}

\subsection{Material}

The composite specimens were prepared by screw in-line type injection molding machine. And the component of composite includes 0,5 , and $10 \mathrm{wt} \% \%$ wollastonite (W) particles, respectively. 


\subsection{Design of Experiments}

The experiments are conducted per the standard orthogonal array. The selection of the orthogonal array is based on the condition that the degrees of freedom for the orthogonal array should be greater than, or equal to, the sum of the wear parameters. In this study, an L27 orthogonal array was chosen that has 27 rows and 13 columns, as shown in the Table 1.

\section{Table 1. Orthogonal array $L_{27}\left(3^{13}\right)$ of Taguchi design}

\begin{tabular}{|c|c|c|c|c|c|c|c|c|c|c|c|c|c|}
\hline $\begin{array}{l}\mathrm{L}_{27}\left(3^{13}\right) \\
\text { test }\end{array}$ & 1 & 2 & 3 & 4 & 5 & 6 & 7 & 8 & 9 & 10 & 11 & 12 & 13 \\
\hline 1 & 1 & 1 & 1 & 1 & 1 & 1 & 1 & 1 & 1 & 1 & 1 & 1 & 1 \\
\hline 2 & 1 & 1 & 1 & 2 & 2 & 2 & 2 & 2 & 2 & 2 & 2 & 2 & 2 \\
\hline 3 & 1 & 1 & 1 & 3 & 3 & 3 & 3 & 3 & 3 & 3 & 3 & 3 & 3 \\
\hline 4 & 1 & 2 & 2 & 2 & 1 & 1 & 1 & 2 & 2 & 2 & 3 & 3 & 3 \\
\hline 5 & 1 & 2 & 2 & 2 & 2 & 2 & 2 & 3 & 3 & 3 & 1 & 1 & 1 \\
\hline 6 & 1 & 2 & 2 & 2 & 3 & 3 & 3 & 1 & 1 & 1 & 2 & 2 & 2 \\
\hline 7 & 1 & 3 & 3 & 3 & 1 & 1 & 1 & 3 & 3 & 3 & 2 & 2 & 2 \\
\hline 8 & 1 & 3 & 3 & 3 & 2 & 2 & 2 & 1 & 1 & 1 & 3 & 3 & 3 \\
\hline 9 & 1 & 3 & 3 & 3 & 3 & 3 & 3 & 2 & 2 & 2 & 1 & 1 & 1 \\
\hline 10 & 2 & 1 & 2 & 3 & 1 & 2 & 3 & 1 & 2 & 3 & 1 & 2 & 3 \\
\hline 11 & 2 & 1 & 2 & 3 & 2 & 3 & 1 & 2 & 3 & 1 & 2 & 3 & 1 \\
\hline 12 & 2 & 1 & 2 & 3 & 3 & 1 & 2 & 3 & 1 & 2 & 3 & 1 & 2 \\
\hline 13 & 2 & 2 & 3 & 1 & 1 & 2 & 3 & 2 & 3 & 1 & 3 & 1 & 2 \\
\hline 14 & 2 & 2 & 3 & 1 & 2 & 3 & 1 & 3 & 1 & 2 & 1 & 2 & 3 \\
\hline 15 & 2 & 2 & 3 & 1 & 3 & 1 & 2 & 1 & 2 & 3 & 2 & 3 & 1 \\
\hline 16 & 2 & 3 & 1 & 2 & 1 & 2 & 3 & 3 & 1 & 2 & 2 & 3 & 1 \\
\hline 17 & 2 & 3 & 1 & 2 & 2 & 3 & 1 & 1 & 2 & 3 & 3 & 1 & 2 \\
\hline 18 & 2 & 3 & 1 & 2 & 3 & 1 & 2 & 2 & 3 & 1 & 1 & 2 & 3 \\
\hline 19 & 3 & 1 & 3 & 2 & 1 & 3 & 2 & 1 & 3 & 2 & 1 & 3 & 2 \\
\hline 20 & 3 & 1 & 3 & 2 & 2 & 1 & 3 & 2 & 1 & 3 & 2 & 1 & 3 \\
\hline 21 & 3 & 1 & 3 & 2 & 3 & 2 & 1 & 3 & 2 & 1 & 3 & 2 & 1 \\
\hline 22 & 3 & 2 & 1 & 3 & 1 & 3 & 2 & 2 & 1 & 3 & 3 & 2 & 1 \\
\hline 23 & 3 & 2 & 1 & 3 & 2 & 1 & 3 & 3 & 2 & 1 & 1 & 3 & 2 \\
\hline 24 & 3 & 2 & 1 & 3 & 3 & 2 & 1 & 1 & 3 & 2 & 2 & 1 & 3 \\
\hline 25 & 3 & 3 & 2 & 1 & 1 & 3 & 2 & 3 & 2 & 1 & 2 & 1 & 3 \\
\hline 26 & 3 & 3 & 2 & 1 & 2 & 1 & 3 & 1 & 3 & 2 & 3 & 2 & 1 \\
\hline 27 & 3 & 3 & 2 & 1 & 3 & 2 & 1 & 2 & 1 & 3 & 1 & 3 & 2 \\
\hline
\end{tabular}

The wear parameters chosen for the experiments and their levels are shown in the Table 2. The experiment consists of 27 tests (each row in the L27 orthogonal array), and the columns are assigned to specific parameters. The first column is assigned to material type, the second column is assigned to sliding speed, and the fifth column is assigned to applied load, with the remaining columns assigned to their interactions (Figure1). The responses to be studied are the weight loss and friction coefficient of composite materials. The tests were replicated, resulting in a total of 81 tests, to allow the analysis of the variance of the results.
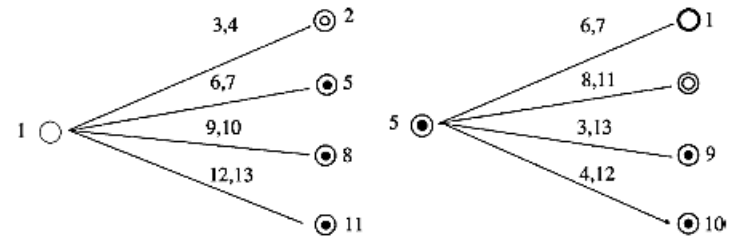

Table 2. Test parameters with their values at three levels

\begin{tabular}{lllll}
\multirow{2}{*}{ Control factors } & \multicolumn{2}{l}{ Level } & & \\
\cline { 2 - 5 } & I & II & III & Units \\
\hline A:Material types & 0 & 5 & 10 & Wt.\% \\
B:Sliding speed & 1 & 1.5 & 2 & $\mathrm{~m} / \mathrm{s}$ \\
C:Applied load & 6 & 10 & 20 & $\mathrm{~N}$ \\
\hline
\end{tabular}

\subsection{Experimental Set Up and Procedure}

The pin-on-disc test apparatus shown in Figure 2 is used to investigate the dry sliding wear characteristics of the composite via the ASTM G99-95 standard. A wear specimen $6 \mathrm{~mm}$ in diameter and $10 \mathrm{~mm}$ in height is cut from samples, machined to size and then polished metallographically. The initial weight of the specimen is measured to $0.0001 \mathrm{~g}$. During the test the pin is pressed against the counterface AISI 4140 steel disc with a hardness of $56 \mathrm{HRC}$. After traversing a fixed $\mathrm{D}$, the specimen is removed, cleaned with acetone, dried, and weighed to determine the mass loss due to wear. The difference in the mass before and after testing gives the dry sliding weight loss of the composite specimen.

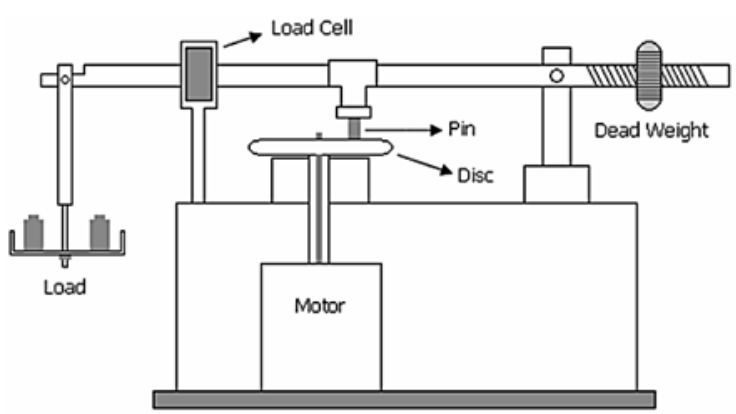

Figure 2. Schematic diagram of wear test rig

\section{Results and Discussions}

The plan of tests was developed with the aim of relating the influence of material types, sliding speed and applied load to determine weight loss and friction coefficient of composite materials. The statistical treatment of the data was made in two phases. The first phase was concerned with the effect of the factors and of the interactions and the ANOVA. The second phase allowed us to obtain the relations between the parameters.

\subsection{Analysis of Factors}

Analyses of the influence of each control factor (material types, sliding speed and applied load) on the weight loss and friction coefficient were performed with a so-called $\mathrm{S} / \mathrm{N}$ response table, using a Minitab 16.1 computer package.

Table 3 shows the experimental plan and their results with calculated $\mathrm{S} / \mathrm{N}$ ratios for weight loss and friction coefficient of the composites. The right side of the table included the results of the measured weight loss, friction coefficient and the calculated $\mathrm{S} / \mathrm{N}$ ratio.

Figure 1. Linear graph $L_{27}\left(3^{13}\right)$ [24]; [25]. 
The response tables of the weight loss and friction coefficient are presented in Table 4 and 5. It indicates the S/N ratio at each level of control factor and how it was changed when settings of each control factor were changed from level 1 to level 3.

Table 3. Orthogonal array L27 (313) of Taguchi design

\begin{tabular}{|c|c|c|c|c|c|c|}
\hline Material type & $\begin{array}{c}\text { Sliding } \\
\text { speed } \\
(\mathrm{m} / \mathrm{s})\end{array}$ & $\begin{array}{c}\text { Applied } \\
\text { load } \\
(\mathrm{N})\end{array}$ & $\begin{array}{c}\text { Weight } \\
\text { Loss } \\
(\mathrm{mg})\end{array}$ & $\begin{array}{c}\mathrm{S} / \mathrm{N} \\
\text { ratios } \\
(\mathrm{dB}) \\
\end{array}$ & $\begin{array}{c}\text { Friction } \\
\text { coefficient }\end{array}$ & $\begin{array}{c}\mathrm{S} / \mathrm{N} \\
\text { ratios } \\
(\mathrm{dB}) \\
\end{array}$ \\
\hline PA6 & 1.0 & 6 & 0.00070 & 63.10 & 0.34 & 9.37 \\
\hline PA6 & 1.0 & 10 & 0.00075 & 62.50 & 0.48 & 6.38 \\
\hline PA6 & 1.0 & 20 & 0.00105 & 59.58 & 0.58 & 4.73 \\
\hline PA6 & 1.5 & 6 & 0.00085 & 61.41 & 0.26 & 11.70 \\
\hline PA6 & 1.5 & 10 & 0.00100 & 60.00 & 0.36 & 8.87 \\
\hline PA6 & 1.5 & 20 & 0.00120 & 58.42 & 0.57 & 4.88 \\
\hline PA6 & 2.0 & 6 & 0.00095 & 60.45 & 0.19 & 14.42 \\
\hline PA6 & 2.0 & 10 & 0.00125 & 58.06 & 0.24 & 12.40 \\
\hline PA6 & 2.0 & 20 & 0.00155 & 56.19 & 0.32 & 9.90 \\
\hline PA6+5\%W & 1.0 & 6 & 0.00055 & 65.19 & 0.13 & 17.72 \\
\hline PA6 $+5 \% W$ & 1.0 & 10 & 0.00065 & 63.74 & 0.29 & 10.75 \\
\hline $\mathrm{PA} 6+5 \% \mathrm{~W}$ & 1.0 & 20 & 0.00090 & 60.92 & 0.41 & 7.74 \\
\hline PA6 $+5 \% \mathrm{~W}$ & 1.5 & 6 & 0.00055 & 65.19 & 0.09 & 20.92 \\
\hline $\mathrm{PA} 6+5 \% \mathrm{~W}$ & 1.5 & 10 & 0.00085 & 61.41 & 0.15 & 16.48 \\
\hline PA6 $+5 \% \mathrm{~W}$ & 1.5 & 20 & 0.00090 & 60.92 & 0.25 & 12.04 \\
\hline $\mathrm{PA} 6+5 \% \mathrm{~W}$ & 2.0 & 6 & 0.00075 & 62.50 & 0.05 & 26.02 \\
\hline $\mathrm{PA} 6+5 \% \mathrm{~W}$ & 2.0 & 10 & 0.00100 & 60.00 & 0.09 & 20.92 \\
\hline PA6 $+5 \% \mathrm{~W}$ & 2.0 & 20 & 0.00105 & 59.58 & 0.12 & 18.42 \\
\hline $\mathrm{PA} 6+10 \% \mathrm{~W}$ & 1.0 & 6 & 0.00015 & 76.48 & 0.12 & 18.42 \\
\hline PA6 $+10 \% W$ & 1.0 & 10 & 0.00050 & 66.02 & 0.18 & 14.89 \\
\hline PA6 $+10 \% W$ & 1.0 & 20 & 0.00060 & 64.44 & 0.21 & 13.56 \\
\hline PA6 $+10 \% W$ & 1.5 & 6 & 0.00035 & 69.12 & 0.07 & 23.10 \\
\hline PA6 $+10 \% W$ & 1.5 & 10 & 0.00070 & 63.10 & 0.10 & 20.00 \\
\hline PA6 $+10 \% \mathrm{~W}$ & 1.5 & 20 & 0.00085 & 61.41 & 0.13 & 17.72 \\
\hline PA6 $+10 \% W$ & 2.0 & 6 & 0.00055 & 65.19 & 0.05 & 26.02 \\
\hline PA6 $+10 \% W$ & 2.0 & 10 & 0.00080 & 61.94 & 0.06 & 24.44 \\
\hline PA6 $+10 \% W$ & 2.0 & 20 & 0.00085 & 61.41 & 0.07 & 23.10 \\
\hline
\end{tabular}

Table 4. The average $S / N$ ratios $(d B)$ response table for weight

\begin{tabular}{cccc} 
& & \multicolumn{2}{c}{ loss } \\
\hline Level & $\begin{array}{c}\text { Material } \\
\text { types }\end{array}$ & $\begin{array}{c}\text { Sliding } \\
\text { speed }(\mathrm{m} / \mathrm{s})\end{array}$ & $\begin{array}{c}\text { Applied } \\
\text { Load } \\
(\mathrm{N})\end{array}$ \\
\hline 1 & 59.97 & 64.66 & 65.40 \\
2 & 62.16 & 62.33 & 61.86 \\
3 & 65.46 & 60.59 & 60.32 \\
Delta & 5.49 & 4.07 & 5.09 \\
Rank & 1 & 3 & 2 \\
\hline
\end{tabular}

The influence of interactions between control factors was also analyzed in the response table. Analysis of interactions between control factors could give very important additional information about the nature of the process under consideration. The control factor with the strongest influence was determined by differences values. The higher the difference, the more influential was the control factor or an interaction of two controls. It can be seen in Table 4, 5 that the strongest influence was exerted by material type, sliding speed and applied load, respectively.

Fig. 3-4(a) and (b) shows the main effects and their interaction plots for the weight loss and friction coefficient of the samples for $\mathrm{S} / \mathrm{N}$ ratios.

Table 5. The average $S / N$ ratios $(d B)$ response table for friction coefficient

\begin{tabular}{cccc}
\hline Level & $\begin{array}{c}\text { Material } \\
\text { types }\end{array}$ & $\begin{array}{c}\text { Sliding } \\
\text { speed }(\mathrm{m} / \mathrm{s})\end{array}$ & $\begin{array}{c}\text { Applied } \\
\text { Load }(\mathrm{N})\end{array}$ \\
\hline 1 & 9.184 & 11.507 & 18.632 \\
2 & 16.778 & 15.079 & 15.014 \\
3 & 20.138 & 19.514 & 12.454 \\
Delta & 10.954 & 8.007 & 6.178 \\
Rank & 1 & 2 & 3 \\
\hline
\end{tabular}

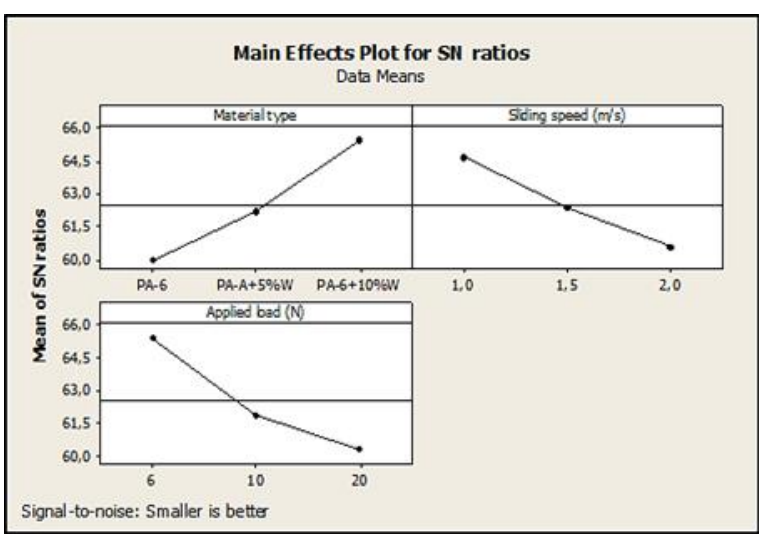

Figure 3(a).Plots for weight loss of samples: Main effects

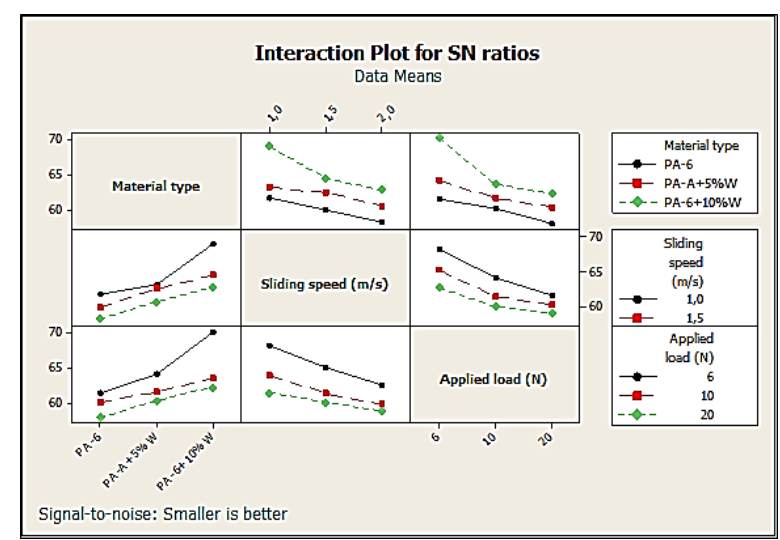

Figure 3(b). Plots for weight loss of samples: Interaction effects 


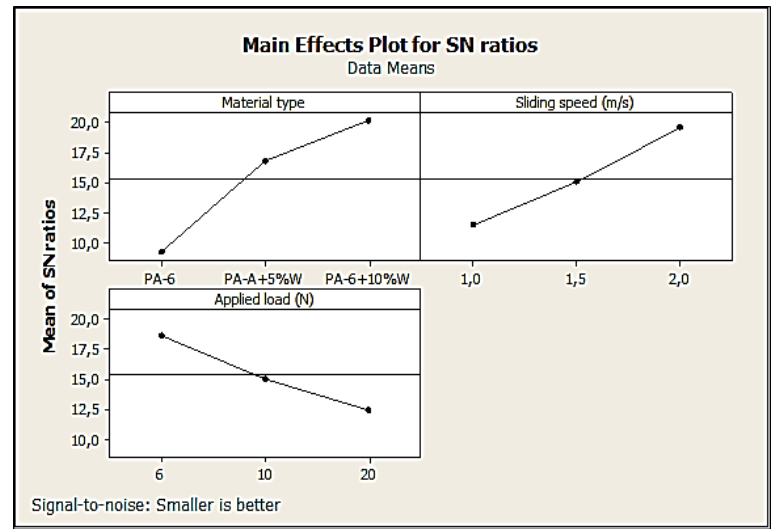

Figure 4(a). Plots for friction coefficient of samples: Main effects

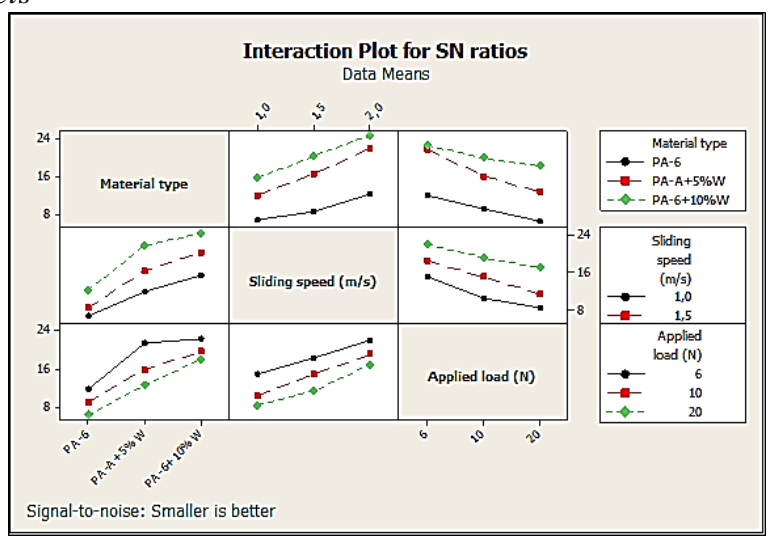

Figure 4(b). Plots for friction coefficient of samples: Interaction effects

The greater is the $\mathrm{S} / \mathrm{N}$ ratio, the smaller is the variance of weight loss and friction coefficient around the desired value. Optimal testing conditions of these control factors could be very easily determined from the response graphs. The graphs show the change of the $\mathrm{S} / \mathrm{N}$ ratio when the setting of the control factor was changed from one level to the other. The best weight loss and friction coefficient were at the higher $\mathrm{S} / \mathrm{N}$ values in the response graphs.

It could be seen in Figure 3 that the initial optimum condition for the tested samples becomes A3B1C1 for main control factors of weight loss. This implies that in order to reduce the weight loss, the sliding speed and load should be lowered, while increasing the filler ratio. It is evident that $\mathrm{Al}+10 \% \mathrm{~W}$ composite material had the greatest effect on influence the optimal testing condition. In addition, the weight loss obviously increased as applied load increased from 6 to $20 \mathrm{~N}$.

The response graph in Figure 4 clearly shows the optimum friction coefficient parameters are obtained at higher $\mathrm{S} / \mathrm{N}$ ratios. Optimum test conditions for the friction coefficient become A3B3C1. The friction coefficient is found to decrease with sliding speed.

\subsubsection{Anova}

The analysis of variance (ANOVA) was used to investigate which design parameters significantly affect the quality characteristic. It was accomplished by separating the total variability of the $\mathrm{S} / \mathrm{N}$ ratios, which is measured by sum of the squared deviations from the total mean $\mathrm{S} / \mathrm{N}$ ratio, into contributions by each of the design parameters and the errors. Examination of the calculated values of Fishers (F) for all control factors also showed a very high influence of material types and low influence of sliding speed on weight loss of PA-6 composite materials (Table 4). The $\mathrm{F}$ value for each design parameters was calculated. Usually, when $F>4$ it means that the design parameter showed a significant effect on the quality characteristic. Otherwise, other factors were neglected. The change of the interactions in the range given in Tables 6 had an insignificant effect on weight loss of materials because of the lower $\mathrm{F}$ value.

Table 6. Results of the ANOVA for weight loss

\begin{tabular}{lcccccc}
\hline Source & $\boldsymbol{D F}$ & $\boldsymbol{S D Q}$ & Variance & $\begin{array}{l}\text { Test } \\
\boldsymbol{F}\end{array}$ & $\boldsymbol{F}_{\text {table }}$ & $\boldsymbol{P}^{\boldsymbol{a}(\boldsymbol{\%})}$ \\
\hline $\begin{array}{l}\text { Material type } \\
\text { Sliding speed }\end{array}$ & 2 & 137.425 & 68.712 & 31.64 & $11.04^{\mathrm{b}}$ & 34.41 \\
$(\mathrm{~m} / \mathrm{s})$ & 2 & 75.109 & 37.554 & 17.3 & $11.04^{\mathrm{b}}$ & 18.81 \\
Applied load (N) & 2 & 122.375 & 61.187 & 28.18 & $11.04^{\mathrm{b}}$ & 30.64 \\
Material type*Sliding speed & 4 & 13.926 & 3.481 & 1.6 & - & 3.49 \\
Material type*Applied load & 4 & 26.391 & 6.597 & 3.04 & - & 6.61 \\
Sliding speed*Applied load & 4 & 6.778 & 1.694 & 0.78 & - & 1.70 \\
Error & 8 & 17.371 & 2.171 & & & \\
Total & 26 & 399.374 & & & & 100 \\
\hline SDQ: sum of squares; DF: degrees of freedom; P: percentage of contribution &
\end{tabular}

a percentage of contribution. $\quad{ }^{b} 99.5 \%$ confidence level.

The last column of the above table indicates the percentage of each factor contribution $(\mathrm{P})$ on the total variation, thus exhibiting the degree of influence on the result. It may be observed in this table that the type of materials $(\mathrm{P}=34.41 \%)$, applied load $(\mathrm{P}=30.64 \%)$ and sliding speed $(\mathrm{P}=18.81 \%)$ had a significant influence on the weight loss. The interactions Material type*Sliding speed $(\mathrm{P}=3.49 \%)$, Material type*Applied load $(\mathrm{P}=6.61$ $\%)$ and Sliding speed*Applied load $(\mathrm{P}=1.70 \%)$ do not present percentages of physical significance of contribution on the weight loss of PA-6 composites.

Table 7. Results of the ANOVA for friction coefficient

\begin{tabular}{lcccccc}
\multicolumn{1}{c}{ Source } & $\boldsymbol{D F}$ & $\boldsymbol{S D Q}$ & Variance & Test $\boldsymbol{F}$ & $\boldsymbol{F}_{\text {table }}$ & $\boldsymbol{P}^{\mathrm{a}}(\boldsymbol{\%})$ \\
\hline Material type & 2 & 566,898 & 283,449 & 1134,50 & $11.04^{\mathrm{b}}$ & 52,89 \\
Sliding speed (m/s) & 2 & 289,632 & 144,816 & 579,62 & $11.04^{\mathrm{b}}$ & 27,02 \\
Applied load (N) & 2 & 173,426 & 86,713 & 347,07 & $11.04^{\mathrm{b}}$ & 16,18 \\
Material type*Sliding speed & 4 & 17,196 & 4,299 & 17,21 & $8.81^{\mathrm{b}}$ & 1,60 \\
Material type*Applied load & 4 & 17,657 & 4,414 & 17,67 & $8.81^{\mathrm{b}}$ & 1,65 \\
Sliding speed*Applied load & 4 & 4,997 & 1,249 & 5,00 & $3.84^{\mathrm{c}}$ & 0,46 \\
Error & 8 & 1,990 & 0,248 & & & \\
Total & 26 & 1071,805 & & & & 100
\end{tabular}

$S D Q$ : sum of squares; $D F$ : degrees of freedom; $P$ : percentage of contribution, a percentage of contribution. b $99.5 \%$ confidence level. ${ }^{\text {c }} 95 \%$ confidence level. 
It can be observed from Table 7 that the material types $(\mathrm{P}=52.89 \%)$, the sliding speed $(\mathrm{P}=27.02 \%)$ and the applied load $(\mathrm{P}=16.18 \%)$ have great influence on the friction coefficient, the material types being the most prominent one. The interactions of Material type*Sliding speed $(\mathrm{P}=1.60 \%)$, Material type*Applied load $(\mathrm{P}=$ $1.65 \%)$ and Sliding speed*Applied load $(\mathrm{P}=0.46 \%)$ present significant percentage contributions on the friction coefficient. All the interactions do not present percentages of physical significance of contribution on the friction coefficient of PA-6 composites.

\section{Conclusions \\ References}

[1] H. Unal, U. Sen and A. Mimaroglu, "Dry sliding wear characteristics of some industrial polymers against steel counterface", Tribology International, vol.37, pp.727-732, 2004.

[2] S. Jeamtrakull, A. Kositchaiyong, T. Markpin, V. Rosarpitak and N. Sombatsompop, "Effects of wood constituents and content, and glass fiber reinforcement on wear behavior of wood/PVC composites", Composites Part B: Engineering, vol.43, no.7, pp.2721-2729, 2012.

[3] N.S.M. El-Tayeb and B.F. Yousif, "Evaluation of glass fiber reinforced polyester composite for multi-pass abrasive wear applications", Wear, vol.262, pp.1140-1151, 2007.

[4] M. Zhang, X. Wang, X. Fu and Y. Xia, "Performance and anti-wear mechanism of $\mathrm{CaCO} 3$ nanoparticles as a green additive in poly-alpha-olefin", Tribology International, vol.42, pp.1029-1039, 2009.

[5] Lin Y-X., Gao C. and Chen M., "Thermomechanical properties and tribological behaviour of $\mathrm{CaCO} 3$ whiskerreinforced polyetheretherketone composites", Proceedings of the Institution of Mechanical Engineers, Part J: Journal of Engineering Tribology, vol.223, pp.1013-1018, 2009.

[6] G. Guofang, Y. Huayong and F. Xin, "Tribological properties of kaolin filled UHMWPE composites in unlubricated sliding", Wear, vol.256, pp.88-94, 2004.

[7] D. Xiang and C. Gu, "A study on the friction and wear behavior of PTFE filled with ultra-fine kaolin particulates" Materials Letters vol.60, pp.689-692, 2006.

[8] H. Unal, F. Findik and A. Mimaroglu,"Mechanical behavior of nylon composites containing talc and kaolin", Journal of Applied Polymer Science, vol.88(7), pp.1694-1697, 2003.

[9] J. Tong, Y. Ma and M. Jiang, "Effects of the wollastonite fiber modification on the sliding wear behavior of the UHMWPE composites", Wear, vol.255, pp.734-741, 2003.

[10] V.K. Srivasstava, J.P. Pathak and K. Tahzibi, "Wear and Friction Characteristics of Mica Filled Fiber Reinforced Epoxy Composites", Wear, vol.152(2),pp.343-350, 1992.

[11] D. Gan, S. Lu, C. Song and W. Wang, "Mechanical properties and frictional behavior of a mica-filled poly(aryl ether ketone) composite", European Polymer Journal, vol.37(7), pp.1359-1365, 2001.

[12] B.A. Mudasar Pasha D., Abdul Budan, S. Basavarajappa, S. Manjunath Yadav and B.A. Nizamuddin, "Studies on wear resistance of PTFE filled with glass and bronze particles based on Taguchi technique", Journal of
- The incorporation of wollastonite particles into PA-6 can either increase or reduce friction coefficient and reduce weight loss of the materials in sliding against AISI 4140 steel disc under dry sliding condition. The optimum wear resistance property was obtained at the wollastonite particle content of $10 \mathrm{wt} . \%$.

- The friction coefficient of pure PA-6 and Wp/PA-6 composites increases with the increase of the load and decreases with the increase of the sliding speed.

- The weight loss of pure PA- 6 and Wp/PA-6 composites increases with the increase of load and sliding speed.

Thermoplastic Composite Materials, vol.26 (2), pp.243-259, 2013.

[13] D. Li, Y. You, X. Deng, W.J. Li and Y. Xie, "Tribological properties of solid lubricants filled glass fiber reinforced polyamide 6 composites", Materials and Design, vol.46, pp.809-815, 2013.

[14] L. Chang, Z. Zhang, H. Zhang and A.K. Schlarb, " On the sliding wear of nanoparticle filled polyamide 66 composites", Composites Science and Technology, vol.66 (16), pp.3188-3198, 2006.

[15] T. Tong, Y. Ma and M. Jiang, "Effects of the wollastonite fiber modification on the sliding wear behavior of the UHMWPE composites", Wear, vol.255, pp.734-741, 2003.

[16] D.H. Gordon and S.N. Kukureka, "The wear and friction of polyamide 46 and polyamide 46/aramid-fibre composites in sliding-rolling contact", Wear, vol.267, pp.669-678, 2009.

[17] Y.K. Chen, O.P. A.S. Modi Mhay, A. Chrysanthou and J.M. O'Sullivan, "The effect of different metallic counterface materials and differentsurface treatments on the wear and friction of polyamide 66 and its composite in rolling-sliding contact”, Wear, 255 714-721, 2003.

[18] S.S. Kim, M.W Shin and H. Jang,"Tribological properties of short glass fiber reinforced polyamide 12 sliding on medium carbon steel", Wear, vol.274-275, pp.34-42, 2012.

[19] S. Yu, H. Hu and J. Yin, "Effect of rubber on tribological behaviors of polyamide 66 under dry and water lubricated sliding”, Wear, vol.265, pp.361-366, 2008.

[20] L. Zhao, L. Zheng, S. Zhao, “Tribological performance of nano-A12O3 reinforced polyamide 6 composites" Materials Letters, vol.60: pp.2590-2593, 2006.

[21] P. Samyn, P. De Baets, G. Schoukens and I. Van Driessche, "Friction, wear and transfer of pure and internally lubricated cast polyamides at various testing scales" Wear, vol.262, pp.1433-1449, 2007.

[22] M. Palabiyik and S. Bahadur, "Tribological studies of polyamide 6 and high-density polyethylene blends filled with PTFE and copper oxide and reinforced with short glass fibers", Wear, vol.253, pp.69-376, 2002.

[23] H. Meng, G.X. Sui, G.Y. Xie and R. Yang, "Friction and wear behavior of carbon nanotubes reinforced polyamide 6 composites under dry sliding and water lubricated condition" Composites Science and Technology, vol.69, pp.606-611, 2009. 
[24 ] P.Ross “Taguchi Techniques for Quality EngineeringLoss Function, Orthogonal Experiments", Parameter and Tolerance Design, McGraw-Hill, New York, 1988.
[25] J.P. Davim, “ Design of optimisation of cutting parameters for turning metal matrix composites based on the orthogonal arrays" Journal of .materials Processing Technology, vol.132: pp.340-344, 2003. 